\title{
Dicentracin-Like from Asian sea bass Fish and Moronecidine-Like from Hippocampus Comes: Two Candidate Antimicrobial Peptides Against Leishmanina major Infection
}

\author{
Mohsen Mohammadi ${ }^{1} \cdot$ Amin Moradi Hasan-Abad ${ }^{2} \cdot$ Parva Dehghani $^{1} \cdot$ Iraj Nabipour $^{1} \cdot$ Mona Roozbehani $^{3}$. \\ Andrew Hemphill ${ }^{4}$. Marzieh Taherzadeh ${ }^{5} \cdot$ Mohammad Ali Mohaghegh $^{6,7} \cdot$ Moradali Fouladvand $^{1,5}$ (1)
}

Accepted: 22 October 2020 / Published online: 29 October 2020

(c) Springer Nature B.V. 2020

\begin{abstract}
Anti-Leishmanial drug therapy faces significant challenges related to cytotoxicity and drug resistance. Thus, new and efficient anti-Leishmanial drugs need to be identified. Due to their broad-spectrum antimicrobial and also immunomodulatory activities, antimicrobial peptides (AMPs) have attracted considerable attention. In this study, we comparatively assessed the anti-Leishmanial activities of two recently identified AMPs (dicentracin-like and moronecidine-like) and the well-known AMP piscidin from the hybrid striped bass. AMPs were first assessed against Leishmania major promastigotes using MTS. Subsequently, macrophages were infected with L. major and treated with AMPs to evaluate anti-amastigotes activity of AMPs, and non-infected macrophages were treated with AMPs to determine cytotoxicity against mammalian cells using MTS. The induction of factors limiting $L$. major growth (IL-12, TNF- $\alpha$ and reactive oxygen species (ROS)) by AMPs was measured by ELISA and dichlorofluorescin-diacetate (DCFH-DA) assay, respectively. Piscidin was more efficacious against $L$. major promastigotes as compared to dicentracine-like or moronocidin-like peptides, whereas, dicentracine-like and moronocidin-like peptide exhibited a higher activity against $L$. major amastigotes compared to piscidin. In turn, piscidin was most cytotoxic in non-infected macrophages compared to the other two AMPs. A direct association was observed between hydrophobicity of AMPs and their anti-promastigote and cytotoxic activities. Dicentracine-like or moronocidin-like peptides induced higher levels of IL-12, TNF- $\alpha$ and ROS in macrophages compared to piscidin. Collectively, our results suggest that dicentracine-like and moronocidin-like peptides represent potentially promising multi-functional therapeutic agents that might not only directly kill $L$. major but also induce anti-Leishmania factors that can limit $L$. major growth and intracellular survival.
\end{abstract}

Keywords Leishmania $\cdot$ Antimicrobial peptides · Anti-amastigote activity · Anti-promastigote activity · Cytotoxicity

\section{Introduction}

The genus Leishmania includes several species, which are the causative agents of either cutaneous, mucocutaneous or visceral leishmaniasis in mostly tropical countries (Ansari et al. 2016). More than 350 million people are at risk of infection, 2.4 million disability-adjusted life years (DALYs)

Electronic supplementary material The online version of this article (https://doi.org/10.1007/s10989-020-10125-4) contains supplementary material, which is available to authorized users.

Moradali Fouladvand

mfooladvand39@yahoo.com

Extended author information available on the last page of the article are lost due to leishmaniasis, and 1-1.5 million cases of cutaneous and 500,000 cases of visceral leishmaniasis occur each year, with 20,000 to 40,000 deaths (Mitra and Mawson 2017; Gharavi et al. 2011a, b). Treatments to control leishmaniasis are mainly based on chemotherapy. Currently used drugs include pentavalent antimonial, amphotericin B, liposomal amphotericin $\mathrm{B}$, miltefosine, paromomycin and pentamidine. However, adverse side effects such as nephrotoxicity and teratogenicity, as well as the prohibitive costs, long duration of treatment, and the potential for resistance formation, are important obstacles that impair treatment efficiency (Sundar and Chakravarty 2015; Ponte-Sucre et al. 2017).

Antimicrobial peptides (AMPs) are biologically active molecules of the innate immune system, particularly in invertebrates (Chiou et al. 2005; Sathyamoorthi et al. 2019; 
Shafiee et al. 2017; Zhang et al. 2009), that were first discovered in the 1980's to exhibit activity against invading pathogens such as bacteria, fungi and viruses (Chiou et al. 2002; Mohammad et al. 2015; Lei et al. 2019; Nayak et al. 2018). They are cationic and hydrophobic peptides, which can get incorporated into the negatively charged microbial membrane through electrostatic interactions, forming pores and leading to cell death(Chiou et al. 2002; Mohammad et al. 2015; Lei et al. 2019). It has been postulated that peptides kill pathogens by several mechanisms, including membrane destabilization, cytoplasmic leakage, collapse of metabolic pathways and also impairment of protein and nucleic acid synthesis (Guilhelmelli et al. 2013; Chifiriuc et al. 2014). Currently, several AMPs are being evaluated in preclinical and clinical trials to treat infectious diseases. Furthermore, two lipopeptides including polymyxin B and polymyxin $\mathrm{E}$ are currently used to treat topical infections and infection caused by multidrug-resistant gram-negative bacteria (Ngamprasertchai et al. 2018; Vaara 2019).

Studies are ongoing to find effective and novel anti-parasitic agents with low side effects in the host (Mor 2009; Torrent et al. 2012). The mechanisms of action of AMPs that lead to anti-Leishmania activities are being studied (Marr et al. 2012). The selectivity toxicity AMPs against Leishmania and the low host cell cytotoxicity renders them highly attractive as peptide-based drugs, either in combination with already approved therapeutics or as a monotherapy (Cobb and Denny 2010).

In our previous study, we characterized two novel antimicrobial peptides, called moronecidin-like (from Asian sea bass fish) and moronecidine-like (from hippocampus comes) peptides, which exhibited efficient antibacterial activity against both gram-positive and gram negative bacteria, and their antibacterial activities were somewhat dependent on electrostatic interactions with bacterial cell walls (Mohammadi et al. 2018; Taheri et al. 2018). In this study, we evaluated the anti-Leishmania properties of moronecidin-like and dicentracin-like AMPs against promastigotes and intracellular amastigotes of $L$. major cultured in macrophages, in comparison to the well-characterized AMP piscidin. The three AMPs exhibited considerable anti-Leishmanial activities, with piscidin being more efficacious against promastigotes, and dicentracine-like and moronecidin-like exhibiting higher and specific activities against the amastigote stage of $L$. major and low host cell toxicity. In macrophages, dicentracine-like and moronecidin-like induced the expression of IL-12, TNF- $\alpha$ and reactive oxygen species (ROS), which contributed to their anti-amastigote activities. This indicates that dicentracine-like and moronecidin-like AMPs should be further considered as potential multifunctional agents for the treatment of Leishmania infections.

\section{Materials and Methods}

\section{Sequence Analysis of Peptides}

To predict physicochemical features (Table 1) of AMPs, their amino acid sequence was submitted in the Prot Param (http://www.expasy.ch/tools/protparam.html). Furthermore, helical wheel projection (http://rzlab.ucr.edu/scripts/wheel /wheel.cgi).

was used to predict helical wheel and hydrophilic and hydrophobic interface on the secondary structure of the peptide.

\section{Synthetic AMPs}

The AMPs (dicentracine-like, moronecidine-like and piscidin) were synthesized by $\mathrm{N}$-(9-fluorenyl) methoxycarbonyl (Fmoc) chemistry (pepmic, Suzhou, Co China). The peptides were $\mathrm{C}$-terminally modified with amid group, and purified using RP-HPLC (SHIMADZU) employing an Inertsil ODS-SP $(4.6 \times 250 \mathrm{~mm} \times 5 \mu \mathrm{m})$ column and elution with a $0-100 \% \mathrm{H} 2 \mathrm{O} /$ acetonitrile gradient containing $0.1 \%$ trifluoroacetic acid (TFA). The homogeneity of peptides was
Table 1 Physicochemical properties of AMPs peptides

\begin{tabular}{|c|c|c|c|}
\hline Name & Dicentracin-like (P1) & Moronecidin-like (P2) & Piscidin (P3) \\
\hline Sequence & $\begin{array}{l}\text { FLRSLLRGAKAI- } \\
\text { YRGARAGWRG }\end{array}$ & $\begin{array}{l}\text { FFRNLWK- } \\
\text { GAKAAFRA- } \\
\text { GHAAWRA }\end{array}$ & $\begin{array}{l}\text { FFHHIFRGIVH- } \\
\text { VGKTIHRLVTG }\end{array}$ \\
\hline Net charge $(\mathrm{Ph} 7) / \mathrm{pI}$ & $6 / 12.18$ & $5.1 / 12.30$ & $3.9 / 11.97$ \\
\hline $\begin{array}{l}\text { Theoretical/ } \\
\text { Observed MW }\end{array}$ & $2531.96 / 2531$ & $2531.96 / 2531$ & $2930.36 / 2930$ \\
\hline Polar/non-polar residues (\%) & $50 / 50$ & $40.91 / 59.09$ & $54.55 / 45.45$ \\
\hline Hydrophobic face residues & F G I L A A LWY L & F A A L G A F W F W & F L V I I I F V G F \\
\hline Non-polar face hydrophobicity $<\mathrm{H}>$ & 1.25 & 1.25 & 1.49 \\
\hline Hydrophobicity $<\mathrm{H}>$ /retention time & $0.321 / 20.518$ & $0.375 / 17.474$ & $0.644 / 21.588$ \\
\hline Water solubility & Good solubility & Good solubility & Poor solubility \\
\hline Hydrophobic moment $<\mu \mathrm{H}>$ & 0.55 & 0.50 & 0.55 \\
\hline
\end{tabular}


evaluated by HPLC, and the molecular masses were determined with mass spectrometry (MS) (Figs. S1, S2 and S3). The lyophilized peptides were suspended in peptide solution ( $0.01 \%$ acid acetic and $0.2 \%$ bovine serum albumin (BSA)), and stored at $20^{\circ} \mathrm{C}$ as peptide stock $(2 \mathrm{mg} / \mathrm{ml})$.

\section{Parasite Culture}

\section{All Culture Materials were Bought from Sigma Aldrich Co (UK)}

Leishmania major promastigotes (MRHO/IR/75/ER) were cultivated at $26^{\circ} \mathrm{C}$ in RPMI 1640 Glutamax medium supplemented with $10 \%$ heat-inactivated fetal bovine serum (FBS), $0.25 \%$ hemin, $0.1 \%$ biotin, $10 \mathrm{mM}$ adenine, $1 \%$ penicillinstreptomycin. For all experiments, stationary-phase L. major promastigotes was used because of high infectivity of $L$. major in this phase (Wozencraft and Blackwell 1987). For this purpose, L. major promastigotes has been cultured for 5 days, were harvested and washed in phosphate buffered saline (PBS) prior to use.

The macrophage cell line RAW264.7 was cultured in DMEM medium containing $10.00 \%$ FBS and penicillinstreptomycin at $37^{\circ} \mathrm{C}$ under $5 \% \mathrm{CO}_{2}$. Macrophages were collected at almost $80 \%$ confluence.

\section{Evaluation of Anti-Leishmanial Activity of AMPs}

L. major promastigotes were counted in a Neubauer hemocytometer and seeded into 96-wel microplates at $1 \times 10^{6}$ cells per well. After $24 \mathrm{~h}$, parasites were treated with 15.5, 31 or $62 \mu \mathrm{M}$ of peptides and incubated for 24 hours at $24{ }^{\circ} \mathrm{C}$. The parasite viability was then determined using the MTS assay as described elsewhere (Lynn et al. 2011). The optical density was read at $570 \mathrm{~nm}$ and wells containing non-treated parasites were used as growth control. Each concentration was assessed in triplicate wells.

\section{Microscopy}

L. major promastigotes were exposed to $15.5,31$ or $62 \mu \mathrm{M}$ of peptides in 96-wel microplates $\left(1 \times 10^{6}\right.$ cells per well $)$ and incubated for $24 \mathrm{~h}$ at $24 \mathrm{C}$. The morphology of treated versus non-treated parasite was then assessed by light microscopy using an inverted microscope at $400 \mathrm{X}$ magnification.

\section{Cytotoxicity in RAW 264.7 Macrophage Cell Line}

RAW 264.7 macrophages were seeded into 96-well microplates at $4 \times 10^{5}$ cells per well. Afterward, $15.5,31$ or $62 \mu \mathrm{M}$ of peptides or peptide solution were added, and cells were cultured for 48 hours at $37{ }^{\circ} \mathrm{C} / 5 \% \mathrm{CO}_{2}$. The viability of macrophages was assessed by MTS assay as previously described
(Lynn et al. 2011). Each peptide concentration was assessed in duplicates. In this experiment, some wells without parasites were used as blank.

\section{Measurements of Anti-amastigote Activity of AMPs}

To assess anti-amastigote activity of AMPs, peritoneal macrophages were obtained from BALB/c mice. These animals were maintained under the animal license permit No. R.BPUMS.REC.1397.064 and experiments were approved by the ethics committee of Bushehr University of Medical Sciences. Macrophages isolated from Balb/c mice were placed into 8-well chamber slides (Thermo Scientific Nunc Lab-Tek, USA ) $\left(8 \times 10^{5}\right.$ marcrophages/well) and were cultured in RPMI 1640 medium containing $10 \% \mathrm{FBS}$ at $37^{\circ} \mathrm{C} / 5 \% \mathrm{CO}_{2}$ for $5 \mathrm{~h}$. Non-adherent cells were removed, and adherent macrophages were infected with stationary phase $L$. major promastigotes at a 1:5 ratio (macrophage/amastigote) and cultured for $5 \mathrm{~h}$. Wells were washed with RPMI 1640 medium three times to remove non-phagocytosed parasites, and infected cells were treated with AMPs peptide ( 15.5 or $31 \mu \mathrm{M})$, ovalbumin-derived peptide (OVA peptide) as non-AMP peptide $(15.5 \mu \mathrm{M})$ or peptide solution (as control infection) for $72 \mathrm{hr}$. Macrophages were then washed with PBS, fixed in methanol for 1 min and stained with 4', 6-diamidino-2-phenylindole (DAPI; SigmaAldrich, St. Louis, USA). The slides were analyzed with NucleoCounter ${ }^{\circledR}$ NC-200 ${ }^{\mathrm{TM}}$ (Chemometec, Allerod, DK) and the number of intracellular parasites in 100 macrophages were counted and expressed relative to those within macrophages treated with peptide solution (control infection) multiply by 100 .

\section{Measurement of Reactive Oxygen Species (ROS) Production in Macrophages in Response to AMP Treatment}

RAW 264.7 macrophage cells $\left(1 \times 10^{5}\right.$ cells $\left./ \mathrm{ml}\right)$ were cultured in 48-well microplate, treated with the AMP peptides (15.5 or $31 \mu \mathrm{M})$, OVA peptide as non-AMPs peptide $(15.5 \mu \mathrm{M})$, the peptide solution as a negative control or LPS as positive control (100 ng/ml), and further cultured for $20 \mathrm{~h}$. The production of ROS within macrophages was measured by 2', 7'-dichlorofluorescin-diacetate (DCFH-DA) assay as described elsewhere (Fan et al. 2017). Briefly, the cells were treated with DCFH-DA, followed by incubation for $1 \mathrm{~h}$ and washed twice with PBS. Finally, intracellular fluorescence was quantified using the fluorescence micro plate reader (BioTek Synergy4, USA) at $485 / 530 \mathrm{~nm}$. 


\section{Assessment of Cytokine Responses in Macrophages in Response to AMP Treatments}

RAW264.7 cells were seeded at $2 \times 10^{4}$ cells/well in a 48-well plate overnight. Cells were exposed to AMPs $(15.5$ or $31 \mu \mathrm{M})$, ovalbumin peptide as non-AMP peptide $(15.5 \mu \mathrm{M})$, peptide solution, or LPS as positive control $(100 \mathrm{ng} / \mathrm{ml})$, and then further cultured for $24 \mathrm{~h}$ at $37 \mathrm{C} / 5 \%$ $\mathrm{CO} 2$. Culture supernatants were collected and cytokine content (TNF- $\alpha$, IL-12) was analyzed by indirect ELISA, according to the protocol provided by manufacture (Abcam, UK).

\section{Statistical Analysis}

The results and graphs are shown as mean the standard deviations (SD) as indicated. Differences between control and peptide-treated samples were analyzed with Prism GraphPad prism 0.8 software. A p-value of less than 0.05 was considered significant.

\section{Results}

\section{Physicochemical Properties of Peptides}

The piscidin peptide exhibited the lowest positive net charge and lower solubility relative to dicentracine-like or monorocidine-like AMPs (Table - 1). Furthermore piscidin had the most hydrophobic non-polar face as compared to dicentracine-like or monorocidine-like. The central residues of the nonpolar face of dicentracine-like and monorocidine-like (9 and 16 residues, respectively) are positioned by low hydrophobic residues including alanine and glycine, whereas the corresponding residues in piscidin are of higher hydrophobic residues (Isoleucine 9 and 16, respectively) (Fig. 1).

\section{Evaluation of Anti-promastigote Activity}

The ability of AMPs to kill promastigotes in the stationaryphase was evaluated to determine the direct cytotoxic activity against $L$. major. MTS assay and microscopic observation were used. MTS data showed (Fig. 2) that all peptides possess dose-dependent cytotoxic activity against $L$. major promastigotes. Dicentracine-like and piscidin exhibit greater activity against $L$. major as compared to morecidine-like with piscidin being the most efficacious of the three AMPs. Microscopy showed that piscidin, in comparison to the other AMPs, induced cellular deformation (rod-like shape) of promastigotes and inhibited cluster formation parasites, even at the lower peptide concentrations $(15.5$ or $31 \mu \mathrm{M})$. At the highest concentrations $(62 \mu \mathrm{M})$, piscidin induced promstigote lysis (Figs. S4, S5, 6). Dicentracine-like exhibited a more pronounced ability to induce cellular deformation (rod-like shape) and inhibited cluster formation of promastigotes at $31 \mu \mathrm{M}$ of peptide concentration.

\section{Evaluation of cytotoxic activity of peptides on macrophage cell line}

The cytotoxic activity of peptides against macrophages was determined using the MTS assay. As shown in Fig. 3, dicentracin-like and moronecidin-like did not exhibit cytotoxic activity against macrophages at $31 \mu \mathrm{M}$ or lesser peptide concentration, but even stimulated macrophage proliferation at $31 \mu \mathrm{M}$ peptide, whereas piscidin was cytotoxic against macrophages at this peptide concentration $(31 \mu \mathrm{M})$.
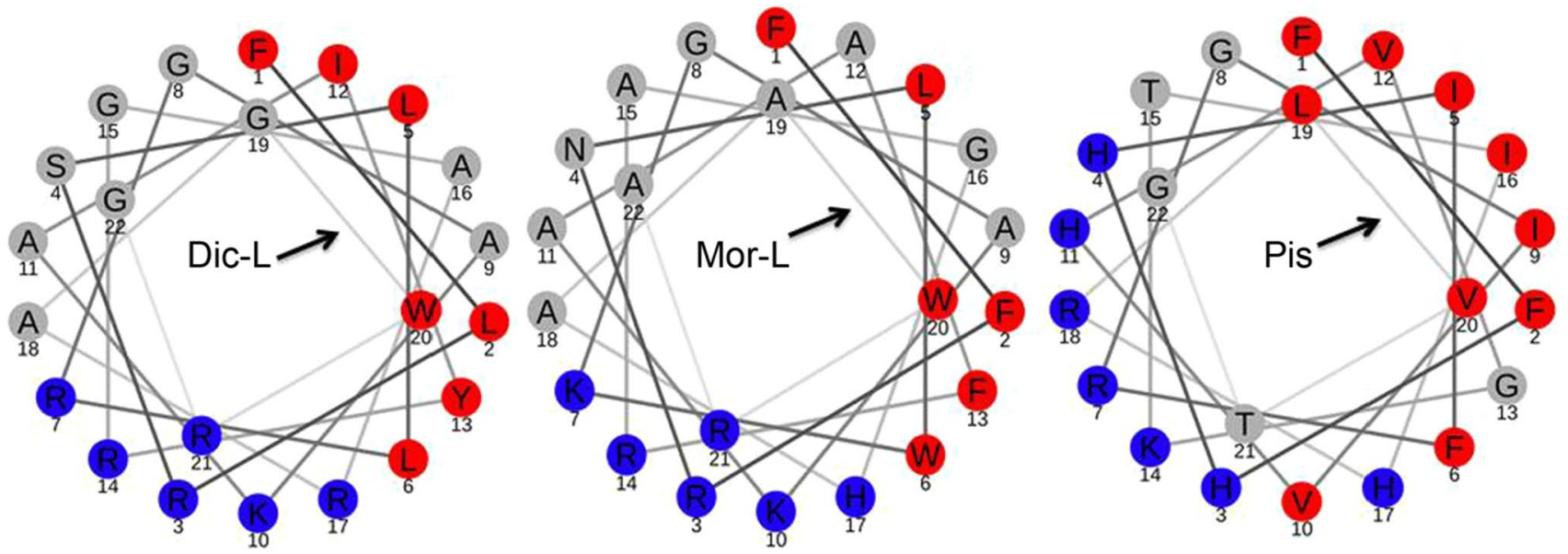

Fig. 1 Helical wheel projections of dicentracine-like (Dic-L) moronecidin-like (Mor-L) and Piscidin (Pis) peptides. Residues are numbered starting from the $\mathrm{N}$ terminus. Residues that are higlyh hydro- phobic and positively charged are shown in red and blue, respectively. Arrows represents the central residues (A9, A16) of the non-polar face in the helical wheel model of AMPs 


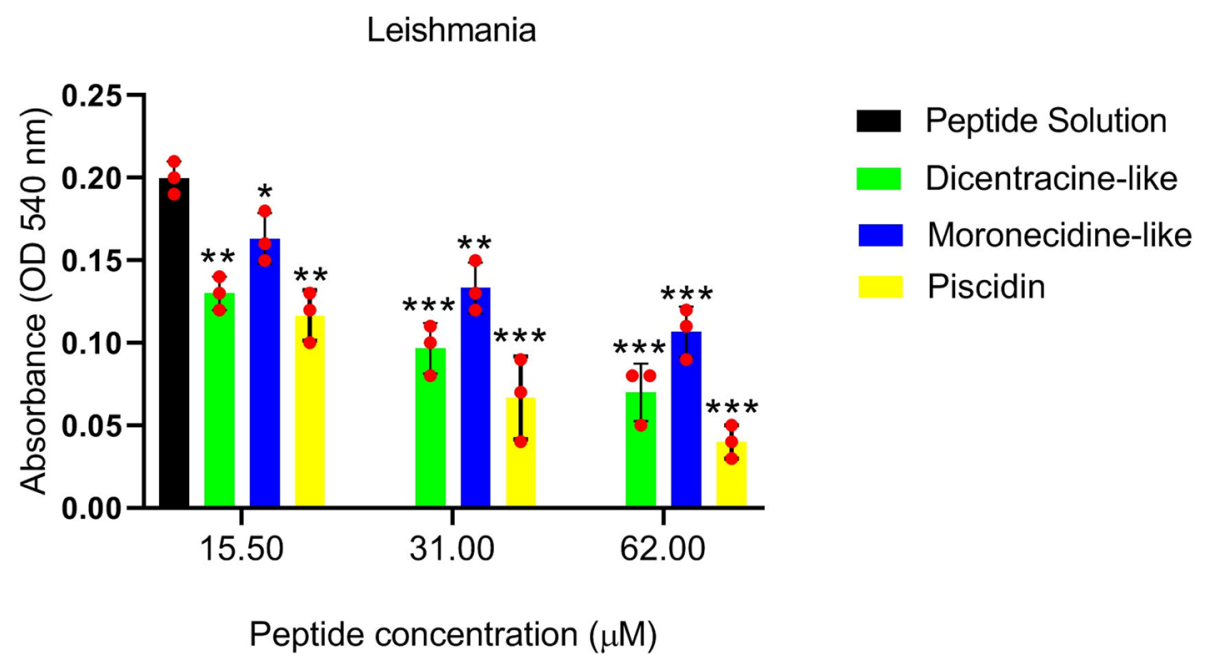

Fig. 2 Direct cytotoxic activity assessment of AMPs against $L$. major promastigotes. The promastigotes were exposed to $15.5,31$ or $62 \mu \mathrm{M}$ or peptide solution. The parasite viability was determined using the MTS assay. Some well without parasites was used as blank, and some control wells with Leishmania and without peptide (peptide solution) are considered as $100 \%$ viable. Three independent experiments were performed, and the values are expressed as mean \pm SD of those three independent experiments. Cytotoxic activity of AMP was compared to peptide solution using one-way analysis of variance (ANOVA). Differences at $p<0.05$ were considered significant $(* * * p<0.001$, $* * p<0.01$, and $* p<0.05$ )
Fig. 3 Cytotoxic activity assessment of AMPs against the macrophage cell line RAW 264.7. RAW 264.7 macrophages were exposed to $15.5,31$ or $62 \mu \mathrm{M}$ of AMPs or peptide solution. The viability of macrophages was determined by MTS assay. The values are expressed as mean \pm SD for three independent experiments. Differences at $p<0.05$ were considered significant $(* * * p<0.001, * * p<0.01$, and $* p<0.05)$. Cytotoxic activity of each peptide was compared to peptide solution using one-way analysis of variance (ANOVA)

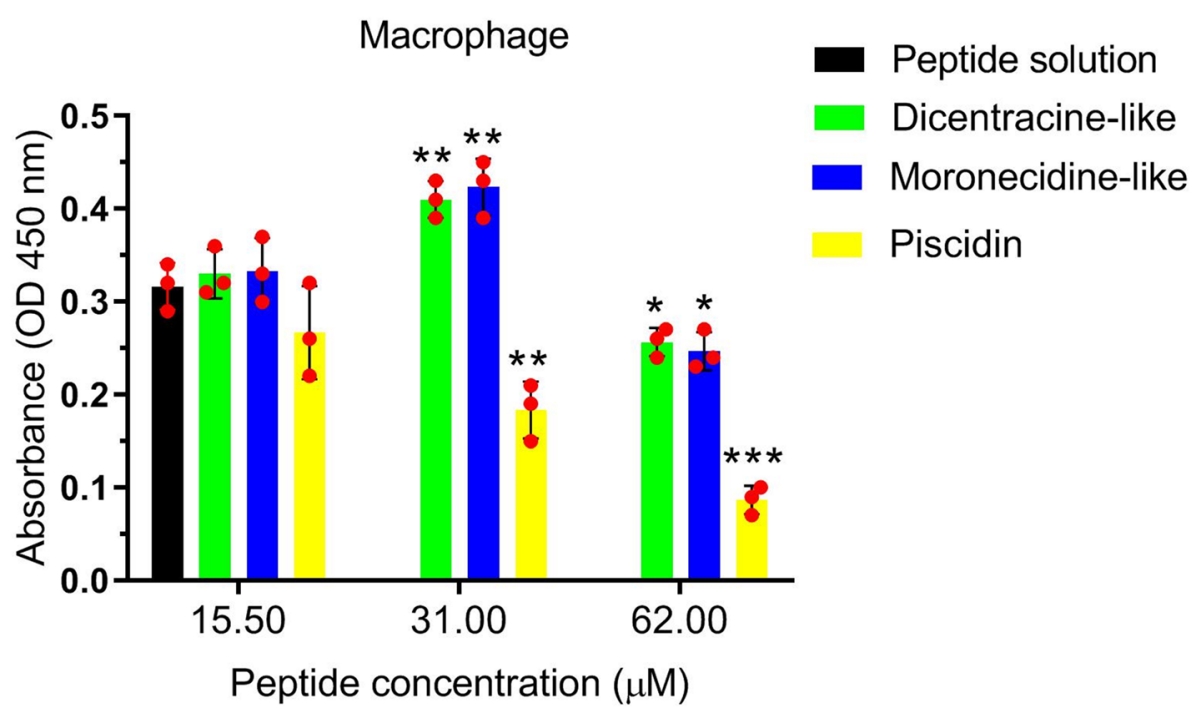

\section{Evaluation of Anti-amastigote Activity of AMPs}

Infected macrophages were treated with the AMPs, and counting of intracellular amastigotes revealed a decreased number of amastigotes in AMPs treated cells relative to those treated with non-AMP peptide. Interestingly moronocidin-like and dicentracin-like showed more pronounced, and virtually similar, anti-amastigote activity than piscidin, and the effect was dose-dependent (Fig. 4).

\section{ROS Production in Macrophages After Exposure to AMPs}

The ability of the peptide to induce ROS production in macrophages was evaluated by DCFH-DA assay. Macrophages treated with moronocidin-like and dicentracin-like produced significantly high amounts of ROS as compared to those treated with piscidin, non-AMP peptide or peptide solution(Fig. 5). An increase in the concentration of 


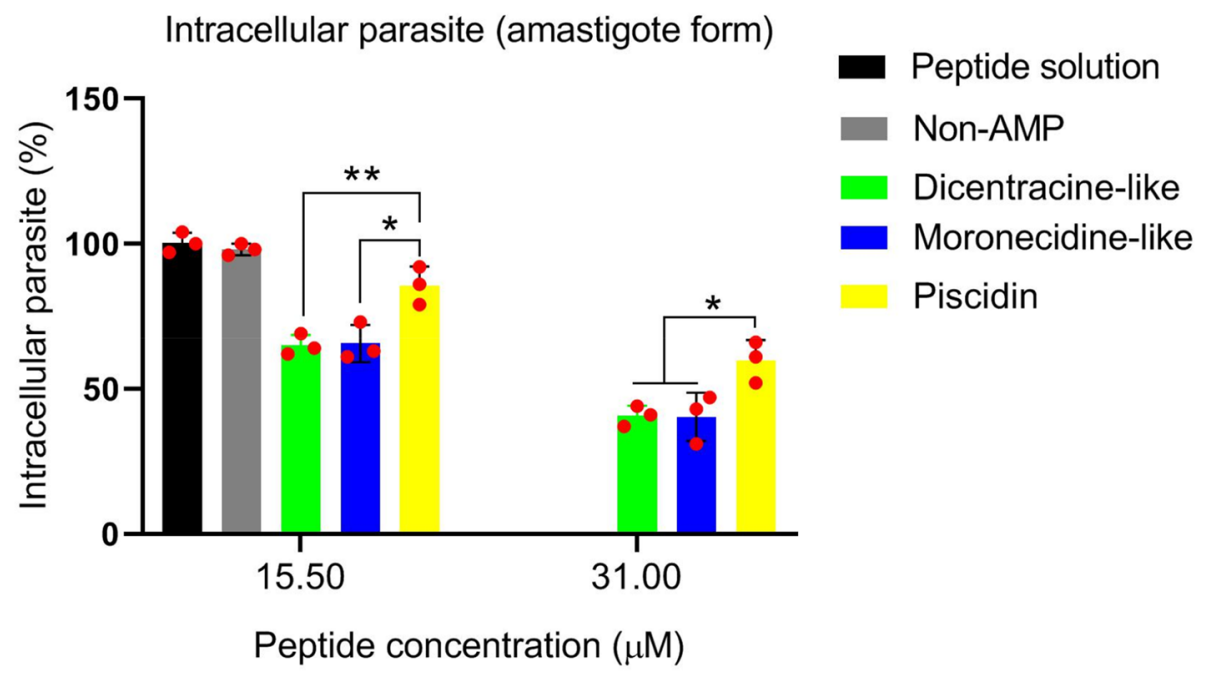

Fig. 4 Cytotoxic activity assessment of the AMPs against intracellular Leishmania amastigotes. Adherent peritoneal macrophages were infected with $L$. major promastigotes and cultured for $5 \mathrm{~h}$, followed by treatment with AMPs $(15.5,31 \mu \mathrm{M})$ or peptide solution. Macrophages were fixed and stained with DAPI, and intracellular amas- tigotes were quantified. The values are expressed as mean \pm SD for three independent experiments. Differences at $p<0.05$ were considered significant $(* * * p<0.001, * * p<0.01$, and $* p<0.05)$. The antiamastigote activity of each peptide was compared to piscidin peptide using one-way analysis of variance (ANOVA).
Fig. 5 Measuring ROS generation in macrophages. RAW 264.7 macrophages were treated with AMPs (15.5 or $31 \mu \mathrm{M})$, non-AMP peptide, peptide solution or LPS, and then intracellular ROS were measured using the fluorescence-based DCFHDA assay at $485 / 530 \mathrm{~nm}$. The values are expressed as mean \pm SD of three independent experiments. Differences at cant $(* * * p<0.001, * * p<0.01$, and $* p<0.05$. The levels of ROS generation of each peptide were compared to peptide solution using one-way analysis of variance (ANOVA) $p<0.05$ were considered signifi-

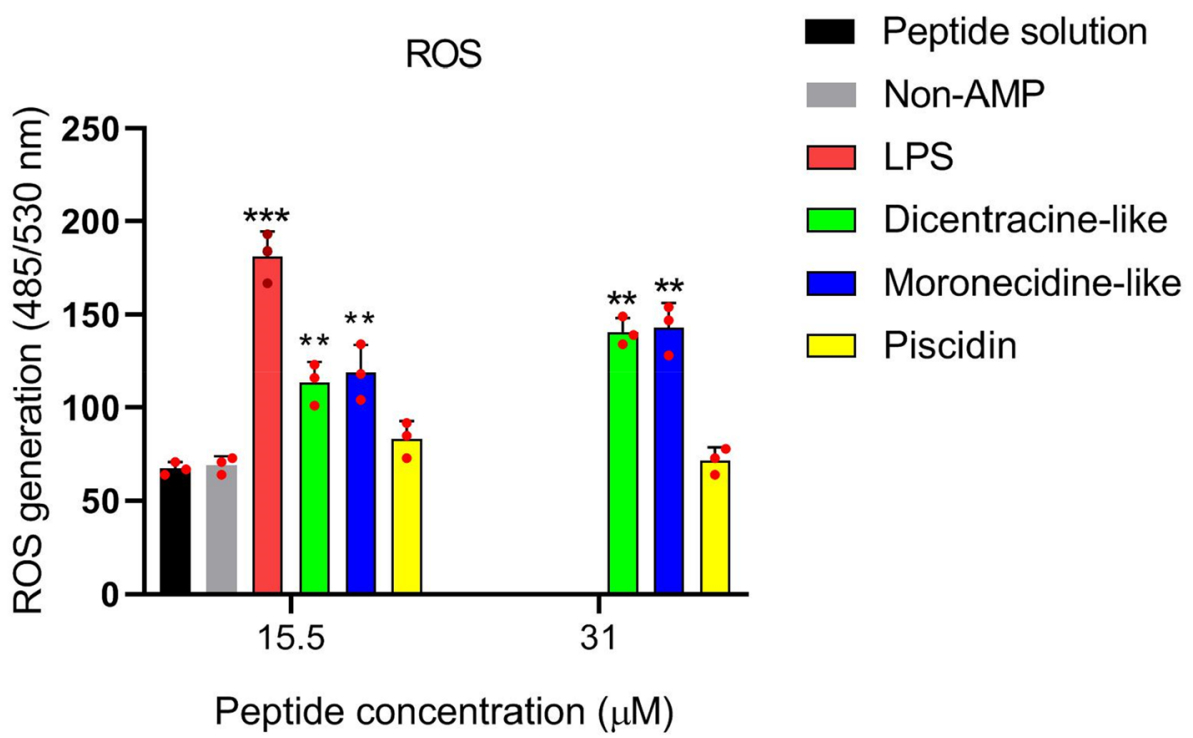

moronocidin-like and dicentracin-like peptides up to $31 \mu \mathrm{M}$ induced the increased ROS production, while no statistically significant change was observed in the production of piscidin-induced ROS.

\section{Cytokine Responses in Macrophages After Exposure to AMPs}

Cytokine response of macrophages was measured after exposure of cells to AMPs or LPS. High levels of TNF- $\alpha$ and IL- 12 were measured in the culture supernatants of macrophages treated with moronocidin-like and dicentracin-like peptides, as compared to those treated with piscidin, non-AMP peptide or peptide solution (Fig. 6). Furthermore no statistically significant difference was observed in the level of piscidin-induced TNF- $\alpha$ and IL-12 as compared to those induced with non-AMP peptide or peptide solution. An increase in the concentration of moronocidin-like and dicentracin-like peptides up to $31 \mu \mathrm{M}$ similarly induced the increased levels of TNF- $\alpha$ and IL-12, while no statistically significant change was observed in the levels of TNF- $\alpha$ and IL-12 produced by piscidin. 


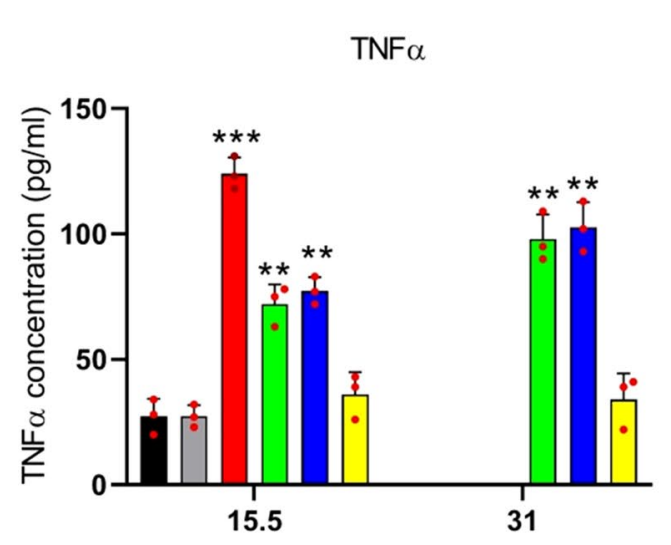

Peptide concentration $(\mu \mathrm{M})$

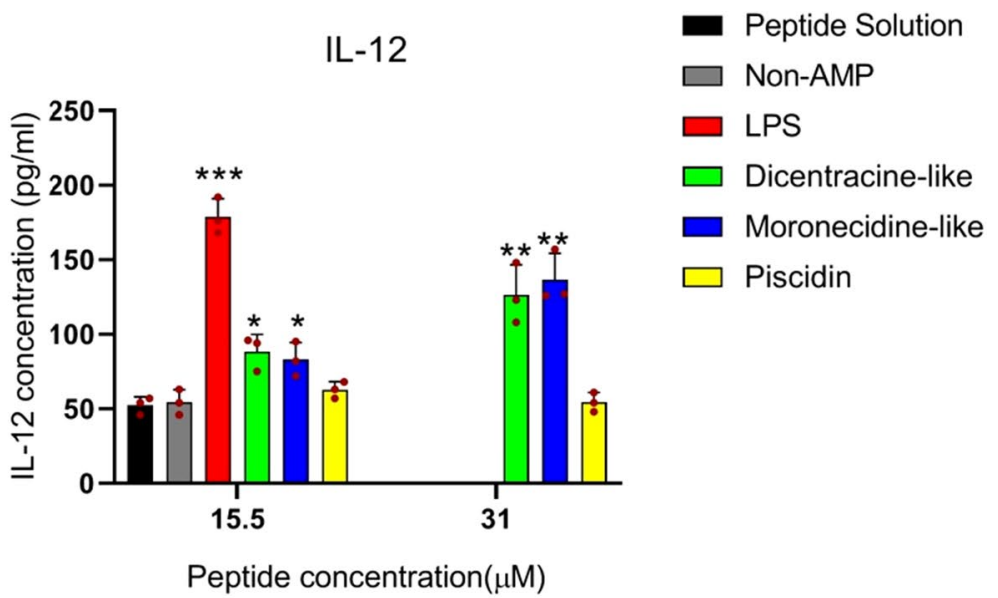

Fig. 6 Secretion of tumor necrosis factor (TNF alpha) and IL-12 by RAW 264.7 macrophages in response to peptides. RAW 264.7 macrophages were treated with AMPs, non-AMP peptide, LPS or peptide solution, and then the presence of TNF- $\alpha$ or IL-12 in culture supernatants was quantified by ELISA. The values are expressed as

\section{Discussion}

Cutaneous leishmaniasis, caused by L. major and L. tropica, is a main health problem in various provinces of Iran (Gharavi et al. 2011a, b). There is no approved vaccine for prophylaxis of leishmaniasis in the endemic regions, and treatment is suboptimal, causing side effects. Consequently, there is an obvious and urgent need for developing affordable, safe and efficacious drugs against leishmaniasis (Fuertes et al. 2008).

In the current study, we compared the anti-L. major activities of the three AMPs dicentracine-like, moronecidin-like, and piscidin (Mohammadi et al. 2018; Taheri et al. 2018). The three AMPs exhibit dose dependent activity against $L$. major promastigotes, with piscidin being the most efficacious one as compared to the other two peptides, and induced promastigote lysis at a high peptide concentration. The most likely explanation for the high cytotoxicity of piscidin against promastigotes may be owing to its high hydrophobic nonpolar face relative to the other two peptides. Prior studies demonstrated that peptides with highly hydrophobic nonpolar face possess more propensities to the cell membrane, which in turn leads to increased cytotoxicity (Irazazabal et al. 2016; Taheri et al. 2019). In addition, piscidin also exhibited the highest cytotoxic activity against the macrophage cell line. This is consistent with earlier studies that had demonstrated the high cytotoxicity activity of piscidin against mammalian cells such as Hela cell and human red blood cells. (Kim et al. 2010; Kumar et al. 2016). In a previous study, we demonstrated that a reduction of hydrophobicity at the nonpolar face of piscidin through amino acid substitution resulted in decreased cytotoxicity (Taheri et al. 2019). mean \pm SD for three independent experiments. Differences at $p<0.05$ were considered significant $(* * * p<0.001, * * p<0.01$, and $* p<0.05$ ). Cytokine concentrations of medium supernatants from AMP treated macrophages were compared to peptide solution using one-way analysis of variance (ANOVA)

In contrast to what was seen with promastigotes, moronecidine- like and dicentracine-like were more potent than piscidin against $L$. major amastigotes. This is consistent with the observation that moronecidine- like and dicentracine-like peptides promoted the proliferation of macrophage cells. $\mathrm{T}$ helper1(Th1)-associated cytokines (especially interferon- $\gamma$, TNF- $\alpha$ and IL-12) are known as the key factors in the induction of protective immunity against L. major infection (Dayakar et al. 2019), this cytokines are up-regulated upon signaling of NF- $\kappa \mathrm{B}$ and MAPK pathways (Wang et al. 2019).

Given that AMPs enhance macrophage function through TLR4-induced NF- $\kappa$ B and MAPK signaling (Wang et al. 2019), we studied the influence of AMPs on the expression and induction of limiting factors on L. major growth (IL-12, TNF- $\alpha$ and ROS) in macrophages.

Dicentracine-like and moronecidin-like peptides were capable to induce IL-12, TNF- $\alpha$ and ROS, while non-AMP peptides did not. This result was consistent with previous study that demonstrated immunomodulatory activities of AMPs through the production of type $1 \mathrm{~T}$ helper (TH1) polarizing cytokines (IL-12 and TNF- $\alpha$ ) (Agier et al. 2015). Furthermore, Zheng et al. (Zheng et al. 2007) demonstrated that Cathelicidin LL-37 (a human AMPs), induced the generation of ROS in macrophages. AMPs-induced IL-12 and TNF- $\alpha$ cytokines could activate NK cells to produce interferon (IFN)- $\gamma$, a key cytokine for polarization of $\mathrm{T}$ cells towards a Th1 immune response, and also activate macrophages cells to produce ROS and nitric oxide (NO), thereby protects the host cells through killing of intracellular amastigotes(Dayakar et al. 2019; Roma et al. 2016).

In this study, dicentracine-like and moronecidin-like treatements induced higher levels IL-12, TNF- $\alpha$ and ROS 
compared to piscidin, and this might be due to the high cytotoxic activity of piscidin against macrophage, leading to the reduction of piscidin-induced productions(IL-12, TNF- $\alpha$ and ROS). Considering that IL-12, TNF- $\alpha$ and ROS act as key factors for intracellular $L$. major amastigote growth inhibition (Roma et al. 2016), the greater anti-amastigote activity of dicentracine-like and moronecidin-like peptides than piscidin peptide is mainly linked to their ability to induce the production of IL-12, TNF- $\alpha$ and ROS (indirect anti-amastigote activity). This function corresponds to the well-known role of AMPs in the innate immune system (Diamond et al. 2009). Furthermore, considering that piscidin peptide was disable to induce IL-12, TNF- $\alpha$ and ROS production, the greater anti-amastigote activity of piscidin peptide compared to non-AMP peptides could be due to its direct cytotoxic activity against intracellular $L$. major amastigote (direct anti-amastigote activity ), following the internalization of piscidin into macrophage cells. This result was consistent with the great cytotoxic activity of piscidn peptide against promastigote form. In agreement with this hypothesis, previous studies demonstrated intracellular antiviral activity of AMPs, via the internalization into infected cell and interruption of viral replication(Chessa et al. 2020).

Taken together, these AMPs could act as multifunctional agent against $L$. major not only through direct killing of $L$. major, but also modulation of proinflamatory cytokines and the activation of macrophage that might synergistically control leishmania infection. However, further experiments will be required to verify the anti-Leishmania activity of theses AMPs in the mouse model.

\section{Conclusions}

In the current study, we characterized two peptides with negligible toxicity (dicentracine-like and moronecidine-like), that not only exhibited direct cytotoxicity against $L$. major but also induced limiting L. major growth (proinflamatory cytokines and ROS) in macrophage cells. These two peptides suggested as attractive and efficient multi-functional therapeutic agent again leishmaniasis.

Acknowledgements We thank Bushehr University of Medical Sciences for providing research budget. This was supported by a research Grant (Code: 1218) from Bushehr University of Medical Sciences.

Availability of Data and Material The authors confirm that the data supporting the findings of this study are available within the manuscript.

\section{Compliance with Ethical Standards}

Conflict of interest The authors declare that there are no conflicts of interest regarding the publication of this article.

\section{References}

Agier J, Efenberger M, Brzezińska-Błaszczyk E (2015) Cathelicidin impact on inflammatory cells. Cent Eur J Immunol 40:225-235

Ansari MY, Equbal A, Dikhit MR, Mansuri R, Rana S, Ali V, Sahoo GC, Das P (2016) Establishment of correlation between in-silico and in-vitro test analysis against Leishmania HGPRT to inhibitors. Int J Biol Macromol 83:78-96

Chessa C, Bodet C, Jousselin C, Wehbe M, Lévêque N, Garcia M (2020) Antiviral and Immunomodulatory Properties of Antimicrobial Peptides Produced by Human Keratinocytes. Front Microbiol 11:1155. DOI https://doi.org/10.3389/fmicb.2020.01155

Chifiriuc MC, Grumezescu AM, Lazar V, Bolocan A, Triaridis S, Grigore R, Bertesteanu S (2014) Contribution of Antimicrobial Peptides to the Development of New and Efficient Antimicrobial Strategies. Curr Proteomics 11:98-107

Chiou PP, Lin CM, Perez L, Chen TT (2002) Effect of cecropin B and a synthetic analogue on propagation of fish viruses in vitro. Mar Biotechnol 4:294-302

Chiou TT, Wu JL, Chen TT, Lu JK (2005) Molecular cloning and characterization of cDNA of penaeidin-like antimicrobial peptide from tiger shrimp (Penaeus monodon). Mar Biotechnol 7:119-127

Cobb SL, Denny PW (2010) Antimicrobial peptides for leishmaniasis. Curr Opin Investig Drugs 11:868-875

Dayakar A, Chandrasekaran S, Kuchipudi SV. Kalangi SK (2019) Cytokines: key determinants of resistance or disease progression in visceral leishmaniasis: opportunities for novel diagnostics and immunotherapy. Front Immunol 10:670

Diamond G, Beckloff N, Weinberg A, Kisich KO (2009) The roles of antimicrobial peptides in innate host defense. Curr Pharm Des 15:2377-2392

Fan C, Wu LH, Zhang GF, Xu F, Zhang S, Zhang X, Sun L, Yu Y, Zhang Y (2017) 4' Hydroxywogonin suppresses lipopolysaccharide-induced inflammatory responses in RAW 264.7 macrophages and acute lung injury mice. PLoS One. https://doi.org/10.1371/ journal.pone.0181191

Fuertes MA, Nguewa PA, Castilla J, Alonso C, Pérez JM (2008) Anticancer compounds as leishmanicidal drugs: challenges in chemotherapy and future perspectives. Curr Med Chem 15:433-439

Gharavi MJ, Nobakht M, Khademvatan SH, Fani F, Bakhshayesh M, Roozbehani M (2011a) The Effect of Aqueous Garlic Extract on Interleukin-12 and 10 Levels in Leishmania major (MRHO/IR/75/ ER) Infected Macrophages. Iranian J Publ Health 40:105-111

Guilhelmelli F, Vilela N, Albuquerque P, Derengowski Lda S, SilvaPereira I, Kyaw CM (2013) Antibiotic development challenges: the various mechanisms of action of antimicrobial peptides and of bacterial resistance. Front Microbiol 4:353-365

Irazazabal LN, Porto WF, Ribeiro SM, Casale S, Humblot V, Ladram A, Franco OL (2016) Selective amino acid substitution reduces cytotoxicity of the antimicrobial peptide mastoparan. Biochim Biophys Acta 1858:2699-2708

Kim JK, Lee SA, Shin S, Lee JY, Jeong KW, Nan YH, Park YS, Shin SY, Kim Y (2010) Structural flexibility and the positive charges are the key factors in bacterial cell selectivity and membrane penetration of peptoid-substituted analog of Piscidin 1. Biochim Biophys Acta 1798:1913-1925

Kumar A, Tripathi AK, Kathuria M, Shree S, Tripathi JK, Purshottam RK, Ramachandran R, Mitra K, Ghosh JK (2016) Single Amino Acid Substitutions at Specific Positions of the Heptad Repeat Sequence of Piscidin-1 Yielded Novel Analogs That Show Low Cytotoxicity and In Vitro and In Vivo Antiendotoxin Activity. Antimicrob Agents Chemother 60:3687-3699

Lei J, Sun L, Huang S, Zhu C, Li P, He J, Mackey V, Coy DH, He Q (2019) The antimicrobial peptides and their potential clinical applications. Am J Transl Res 11:3919-3931 
Lynn MA, Kindrachuk J, Marr AK, Jenssen H, Panté N, Elliott MR, Napper S, Hancock RE, McMaster WR (2011) Effect of BMAP28 antimicrobial peptides on Leishmania major promastigote and amastigote growth: role of leishmanolysin in parasite survival. PLoS Negl Trop Dis. https://doi.org/10.1371/journal.pntd.00011 41

Marr AK, McGwire BS, McMaster WR (2012) Modes of action of Leishmanicidal antimicrobial peptides. Future Microbiol 7:1047-1059

Mitra AK, Mawson AR (2017) Neglected tropical diseases: epidemiology and global burden. Trop Med Infect Dis. https://doi. org/10.3390/tropicalmed2030036

Mohammad H, Thangamani S, Seleem MN (2015) Antimicrobial peptides and peptidomimetics - potent therapeutic allies for staphylococcal infections. Curr Pharm Des 21:2073-2088

Mohammadi M, Taheri B, Momenzadeh N, Salarinia R, Nabipour I, Farshadzadeh Z, Bargahi A (2018) Identification and characterization of novel antimicrobial peptide from hippocampus comes by in silico and experimental studies. Mar Biotechnol 20:718-728

Mor A (2009) Multifunctional host defense peptides: antiparasitic activities. Febs j 276:6474-6482

Nayak T, Mandal SM, Neog K, Ghosh AK (2018) Characterization of a Gloverin-Like Antimicrobial Peptide Isolated from Muga Silkworm, Antheraea assamensis. Int J Pept Res Ther 24::337-346. DOI https://doi.org/10.1007/s10989-017-9618-0

Ngamprasertchai T, Boonyasiri A, Charoenpong L, Nimitvilai S, Lorchirachoonkul N, Wattanamongkonsil L, Thamlikitkul V (2018) Effectiveness and safety of polymyxin B for the treatment of infections caused by extensively drug-resistant Gram-negative bacteria in Thailand. Infect Drug Resist 11:1219-1224

Gharavi MJ, Nobakht M, Khademvatan SH, Bandani E, Bakhshayesh M, Roozbehani M (2011b) The Effect of Garlic Extract on Expression of INFy And Inos Genes in Macrophages Infected with Leishmania major. Iranian J Parasitol 6:74-81

Ponte-Sucre A, Gamarro F, Dujardin JC, Barrett MP, López-Vélez R, García-Hernández R, Pountainn AW, Mwenechanya R, Papadopoulou B (2017) Drug resistance and treatment failure in leishmaniasis: A 21st century challenge. PLoS Negl Trop Dis. https:// doi.org/10.1371/journal.pntd.0006052

Roma EH, Macedo JP, Goes GR, Gonçalves JL, Castro W, Cisalpino D, Vieira LQ (2016) Impact of reactive oxygen species (ROS) on the control of parasite loads and inflammation in Leishmania amazonensis infection. Parasit Vectors. https://doi.org/10.1186/ s13071-016-1472-y

Sathyamoorthi A, Kumaresan V, Palanisamy R, Pasupuleti M, Arasu MV, Al-Dhabi NA, Marimuthu K, Amin SN, Arshad A, Yusoff
FM (2019) Therapeutic cationic antimicrobial peptide (CAP) derived from fish aspartic proteinase Cathepsin D and its antimicrobial mechanism. Int J Pept Res Ther 25:93-105

Shafiee F, Minaiyan G, Moazen F, Jahanian-Najafabadi A (2017) Recombinant Production and Intein-Mediated Purification of an Antimicrobial Peptide, BR2. Int J Pept Res Ther 23::501-507. DOI https://doi.org/10.1007/s10989-017-9583-7

Sundar S, Chakravarty J (2015) An update on pharmacotherapy for leishmaniasis. Expert Opin Pharmacother 16:237-252

Taheri B, Mohammadi M, Momenzadeh N, Farshadzadeh Z, Roozbehani M, Dehghani P, Hajian S, Darvishi S, Shamseddin J (2019) Substitution of lysine for isoleucine at the center of the nonpolar face of the antimicrobial peptide, piscidin-1, leads to an increase in the rapidity of bactericidal activity and a reduction in toxicity. Infect Drug Resist 12:1629-1647

Taheri B, Mohammadi M, Nabipour I, Momenzadeh N, Roozbehani M (2018) Identification of novel antimicrobial peptide from Asian sea bass (Lates calcarifer) by in silico and activity characterization. PLoS One. https://doi.org/10.1371/journal.pone.0206578

Torrent M, Pulido D, Rivas L, Andreu D (2012) Antimicrobial peptide action on parasites. Curr Drug Targets 13:1138-1147

Vaara M (2019) Polymyxin derivatives that sensitize Gram-Negative bacteria to other antibiotics. Molecules. https://doi.org/10.3390/ molecules 24020249

Wang S, Ye Q, Wang K, Zeng X, Huang S, Yu H, Ge Q, Qi D, Qiao S (2019) Enhancement of macrophage function by the antimicrobial peptide sublancin protects mice from methicillin-resistant Staphylococcus aureus. J Immunol Res 2019:3979-352

Wozencraft A, Blackwell J (1987) Increased infectivity of stationaryphase promastigotes of Leishmania donovani: correlation with enhanced C3 binding capacity and CR3-mediated attachment to host macrophages. Immunology 60:559

Zhang W, Li Z, Miao X, Zhang F (2009) The screening of antimicrobial bacteria with diverse novel nonribosomal peptide synthetase (NRPS) genes from South China sea sponges. Mar Biotechnol 11:346-355

Zheng Y, Niyonsaba F, Ushio H, Nagaoka I, Ikeda S, Okumura K, Ogawa H (2007) Cathelicidin LL-37 induces the generation of reactive oxygen species and release of human alpha-defensins from neutrophils. Br J Dermatol 157:1124-1131

Publisher's Note Springer Nature remains neutral with regard to jurisdictional claims in published maps and institutional affiliations.

\section{Affiliations}

\section{Mohsen Mohammadi ${ }^{1}$. Amin Moradi Hasan-Abad ${ }^{2} \cdot$ Parva Dehghani $^{1} \cdot \operatorname{Iraj}$ Nabipour ${ }^{1} \cdot$ Mona Roozbehani $^{3}$. Andrew Hemphill ${ }^{4}$ Marzieh Taherzadeh ${ }^{5} \cdot$ Mohammad Ali Mohaghegh $^{6,7} \cdot$ Moradali Fouladvand $^{1,5}$ (i)}

Mohsen Mohammadi

mmohamadi1986@yahoo.com; mohammadi@pbums.ac.ir

Amin Moradi Hasan-Abad

amin.moradi63@yahoo.com

Mona Roozbehani

mona.roozbehani@yahoo.com

Andrew Hemphill

andrew.hemphill@vetsuisse.unibe.ch
1 The Persian Gulf Marine Biotechnology Research Center, The Persian Gulf Biomedical Sciences Research Institute, Bushehr University of Medical Sciences, Bushehr, Islamic Republic of Iran

2 School of Advanced Technologies in Medicine, Department of Medical Biotechnology - Tehran, Tehran University of Medical Sciences, Tehran, Islamic Republic of Iran

3 Department of Parasitology and Mycology, School of Medicine, Iran University of Medical Sciences, Tehran, Islamic Republic of Iran 
4 Institute of Parasitology, Vetsuisse Faculty, University of Bern, Bern, Switzerland

5 Department of Microbiology and Parasitology, School of Medicine, Bushehr University of Medical Sciences, Moallem Street, Bushehr 7514633196, Islamic Republic of Iran
6 Department of Laboratory Sciences, School of Paramedical Sciences, Torbat Heydariyeh University of Medical Sciences, Torbat Heydariyeh, Islamic Republic of Iran

7 Health Sciences Research Center, Torbat Heydariyeh University of Medical Sciences, Torbat Heydariyeh, Islamic Republic of Iran 